\title{
A modular map of Bradykinin-mediated inflammatory signaling network
}

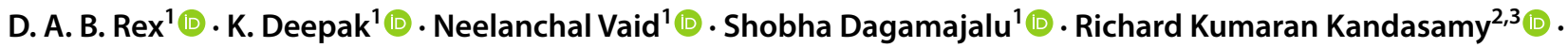 \\ Trude Helen $\mathrm{Flo}^{2}$ (D) T. S. Keshava Prasad ${ }^{1}$ (1)
}

Received: 8 August 2021 / Accepted: 3 October 2021 / Published online: 29 October 2021

(C) The International CCN Society 2021

\begin{abstract}
Bradykinin, a member of the kallikrein-kinin system (KKS), is associated with an inflammatory response pathway with diverse vascular permeability functions, including thrombosis and blood coagulation. In majority, bradykinin signals through Bradykinin Receptor B2 (B2R). B2R is a G protein-coupled receptor (GPCR) coupled to G protein family such as $\mathrm{G}_{\mathrm{qs}}$, $\mathrm{G} \alpha_{\mathrm{q}} / \mathrm{G} \alpha_{11}, \mathrm{G} \alpha_{i 1}$, and $\mathrm{G} \beta 1_{\gamma} 2$. B2R stimulation leads to the activation of a signaling cascade of downstream molecules such as phospholipases, protein kinase C, Ras/Raf-1/MAPK, and PI3K/AKT and secondary messengers such as inositol-1,4,5trisphosphate, diacylglycerol and $\mathrm{Ca}^{2+}$ ions. These secondary messengers modulate the production of nitric oxide or prostaglandins. Bradykinin-mediated signaling is implicated in inflammation, chronic pain, vasculopathy, neuropathy, obesity, diabetes, and cancer. Despite the biomedical importance of bradykinin, a resource of bradykinin-mediated signaling pathway is currently not available. Here, we developed a pathway resource of signaling events mediated by bradykinin. By employing data mining strategies in the published literature, we describe an integrated pathway reaction map of bradykinin consisting of 233 reactions. Bradykinin signaling pathway events included 25 enzyme catalysis reactions, 12 translocations, 83 activation/inhibition reactions, 11 molecular associations, 45 protein expression and 57 gene regulation events. The pathway map is made publicly available on the WikiPathways Database with the ID URL: https://www.wikipathways.org/index.php/ Pathway:WP5132. The bradykinin-mediated signaling pathway map will facilitate the identification of novel candidates as therapeutic targets for diseases associated with dysregulated bradykinin signaling.
\end{abstract}

Keywords Bradykinin storm · Post-translational modifications $\cdot$ Protein-protein interactions $\cdot$ Signaling pathways

$\begin{array}{ll}\text { Abbreviations } \\ \text { BK } & \text { Bradykinin } \\ \text { KKS } & \text { Kallikrein-kinin system } \\ \text { RAS } & \text { Renin-angiotensin system } \\ \text { B1R } & \text { Bradykinin receptor B1 } \\ \text { B2R } & \text { Bradykinin receptor B2 }\end{array}$

Shobha Dagamajalu shobha_d@yenepoya.edu.in

T. S. Keshava Prasad keshav@yenepoya.edu.in

D. A. B. Rex rexprem@yenepoya.edu.in

K. Deepak newis27deepak@gmail.com

Neelanchal Vaid vneelanchal@gmail.com

Richard Kumaran Kandasamy richard.k.kandasamy@ntnu.no
PK Plasma kallikrein

GPCR G-protein coupled receptor

PIP2 Phosphatidylinositol 4, 5-bisphosphate

ACE Angiotensin-converting enzyme

NO Nitric oxide
Trude Helen Flo

trude.flo@ntnu.no

1 Center for Systems Biology and Molecular Medicine, Yenepoya Research Centre, Yenepoya (Deemed to be University), Mangalore 575018, India

2 Centre of Molecular Inflammation Research (CEMIR), and Department of Clinical and Molecular Medicine (IKOM), Norwegian University of Science and Technology, 7491 Trondheim, Norway

3 College of Medicine, Mohammed Bin Rashid University of Medicine and Health Sciences, Dubai, UAE 
PGI2 Prostaglandin I2

eNOS Endothelial nitric oxide synthase

\section{Introduction}

Bradykinin is a potent, short-lived vasoactive peptide, which acts as an inflammatory mediator. It is a constituent of the kallikrein-kinin system (KKS). Kinins are released from high molecular weight kininogens (HMWK) and low molecular weight kininogens (LMWK) by the action of plasma kallikrein (PK) or tissue kallikrein (TK). HMWK and LMWK are the two components of KKS and play a major role in the synthesis of bradykinin (Leeb-Lundberg et al. 2005; Vandell et al. 2008; Hofman et al. 2016a, b; Nokkari et al. 2018). The LMWK is cleaved by tissue kallikrein into a 10-amino-acid peptide, lysyl-bradykinin (kallidin), with a sequence Lys-Arg-Pro-Pro-Gly-Phe-SerPro-Phe-Arg (Kaplan et al. 2002). The action of a plasma amino-peptidase on kallidin cleaves the $\mathrm{N}$-terminal Lys and liberates bradykinin as a 9-amino-acid peptide. The other arm of the cascade comprises factor XII, an initiating protein that binds to charged surface macromolecules and forms factor XIIa, which converts prekallikrein into active plasma kallikrein. Further, HMWK is cleaved by plasma kallikrein into nonapeptide bradykinin (Kaplan et al. 2002; Kenniston et al. 2014). Degradation of bradykinin occurs by the action of kininase I and kininase II enzymes. Kininase I, also known as plasma carboxypeptidase, removes the $\mathrm{C}$ - terminal Arg from bradykinin and kallidin to form Des-Arg9-bradykinin and Des-Arg10-kallidin, respectively. Kininase II is similar to angiotensin-converting enzyme (ACE) in function and metabolizes bradykinin into two $\mathrm{C}$ - terminal dipeptides and a heptapeptide (Kaplan et al. 2002).

Bradykinin is released in pathological conditions such as trauma and inflammation, which binds to its kinin receptors. It is encoded by exon 10 of the kininogen gene located on chromosome 3 (3q26) in humans (Fong et al. 1991). Bradykinin activates several second messenger systems, thereby regulating blood-brain barrier permeability, blood pressure, pain perception, glutamate release from astrocytes, neuronal differentiation, and nitric oxide production (Whalley et al. 2012).

The action of bradykinin is mediated through an interaction with cell surface bradykinin receptors. Bradykinin Receptor B1 (B1R) and Bradykinin Receptor B2 (B2R) are the two subtypes of bradykinin receptors, which belong to the GPCR family (Leeb-Lundberg et al. 2005; Marceau et al. 2020). B1R encoded by the gene BDKRB 1 has minimal expression in healthy tissues, and its expression is induced only under special conditions such as injury and inflammation (Couture et al. 2001; Qadri and Bader 2018). In most cases, bradykinin acts through the B2R, which is encoded by the gene BDKRB2. B2R is ubiquitously expressed and implicated in vasodilation, osmoregulation, smooth muscle contraction, and nociceptors' activation (Leeb-Lundberg et al. 2005). B2R expression upregulated under pathological conditions of tissue injury due to oxidative stress, proinflammatory stimuli such as exposure to lipopolysaccharides, endotoxins, cytokines (IL-1beta and TNF-alpha) and vasoactive peptide stimuli as it is seen in the renin-angiotensin system (RAS) (Marceau et al. 2002; Tschope et al. 2002; Bossi et al. 2009; Jaffa et al. 2012; Naffah-Mazzacoratti Mda et al. 2014).

Bradykinin stimulates $B 2 R$ coupled with $G$ proteins and activates signaling molecules such as protein kinase C (PKC), phospholipase C (PLC), mitogen-activated protein kinases (MAPKs), phosphoinositide-3 kinase (PI3K)/ $\mathrm{AKT}$ and second messengers $\mathrm{IP}_{3}$ (inositol triphosphate), diacylglycerol (DAG) and $\mathrm{Ca}^{2+}$ ions (Kakoki and Smithies 2009; Dong et al. 2015; Wang et al. 2017). These second messengers mediate signaling mechanisms (e.g., nitric oxide or prostaglandin production) (Kakoki and Smithies 2009). Besides, bradykinin is also known to be involved in the activation of inflammatory cytokines. Previous studies have demonstrated that bradykinin-induced activation of MAPKs is involved in the upregulation of several cytokines such as $I L-6, I L-1 \beta, I L-8$ and $I L-2$ (Paegelow et al. 1995; Pan et al. 1996; Huang et al. 2003; Meini et al. 2011; Yang et al. 2018) which are implicated in inflammation, respiratory, gastrointestinal, cardiac, neuronal, ophthalmologic and dermatological problems. Recent reports have shown that bradykinin storm may be responsible for the more severe symptoms of Coronavirus disease (COVID-19) (Garvin et al. 2020; Roche and Roche 2020; Wilczynski et al. 2021). Some reports suggest that $\mathrm{B} 2 \mathrm{R}$ forms a complex with ACE, and this is thought to play a role in cross-talk between the RAS and the KKS (da Costa et al. 2014). Accumulation of bradykinin is implicated in angioedema by genetic defects and ACE inhibitors (Bas et al. 2007). Besides, bradykinin also plays a major role in cancer progression mechanisms (Stewart et al. 2002), for instance, with increased lung cancer risks (Kmietowicz 2018) and proliferation and migration in gastric cancers (Wang et al. 2017), in addition to allergic rhinitis, asthma, and anaphylaxis (Kaplan et al. 2002).

Recent computational analyses suggested that genes related to the bradykinin were up-regulated in bronchoalveolar lavage (BAL) samples of COVID-19 patients. The system implicates the core of the mechanisms triggering the adverse array of symptoms such as muscle pain, fatigue, nausea, vomiting, diarrhoea, headaches, and reduced cognitive function (Garvin et al. 2020). Recent reports show that SARS-CoV-2 employs its spike protein (S) antigen to interact with ACE2 and invade target cells (Astuti and Ysrafil 2020; Zhang et al. 2020). The loss of ACE2 activity and subsequent rise in Angiotensin-II 
leads to a fall in ACE function through a negative feedback loop, ultimately resulting in raised bradykinin levels (Zhu et al. 2010). The increase of bradykinin may be due to the increases in the density of mast cells in the lungs of COVID-19 patients (Motta Junior et al. 2020). Even though several studies have been conducted at the molecular level to deduce the bradykinin signaling pathways, an organized network of molecular reactions induced by bradykinin is not publicly available. Therefore, we curated bradykinin-induced reactions from the literature and organized them into a dataset of molecular reactions. We developed a resource of signaling events mediated by bradykinin, similar to the previously published signaling pathways of IL-18, IL-10, IL-33, endothelin, oncostatin $\mathrm{M}$ and AXL, available in the NetPath and Wikipathways database (Dey et al. 2013; Soman et al. 2013; Verma et al. 2016; Pinto et al. 2018; Rex et al. 2020; Dagamajalu et al. 2021a, 2021b).

\section{Methodology}

We carried out a literature survey of articles related to bradykinin-mediated signaling. The articles were fetched from PubMed using query terms ("Bradykinin" OR "BK" OR "BK receptor" OR "B ${ }_{1}$ receptor" OR "BK receptor B1" OR "BDKRB1" OR "B1R" OR"B ${ }_{2}$ receptor" OR "BK receptor B2" OR "BDKRB2" OR "B2R") AND ("pathway" OR "signaling" OR "signalling" OR "induced pathway" OR "induced signaling" OR "induced signalling"). The research articles were screened manually to evaluate the presence of bradykinin-induced signaling events. The systematic manual curation of signaling events was done based on the previously described PathBuilder tool, NetSlim and NetPath annotation criteria (Kandasamy et al. 2009, 2010; Raju et al. 2011). Accordingly, molecular events induced or influenced by bradykinin were included in the pathway. Further, curated downstream molecules were categorized into activation/inhibition, post-translational modifications (PTMs), translocation, molecular association, gene regulation and protein expression events. Additionally, information about cell lines used in the experiment, type of experiment, gene and protein regulation type (upregulation/downregulation) and PTMs (site and residue wherever available) were also curated. The curated information was further subjected to quality control through an internal review by a couple of experienced curators. Each described signaling event in the pathway was hyperlinked to the abstracts of corresponding articles from where it was retrieved.

PathVisio software used to depict pathway map of bradykinin mediated molecular signaling events (Kutmon et al. 2015).

\section{Results}

In the current study, the PubMed search using query terms fetched 4444 articles related to the bradykinin signaling pathway until September 2020. These articles were carefully reviewed based on our NetPath annotation criteria and shortlisted into 400 articles. The annotated articles provided several molecular reactions such as 11 molecular interactions, 25 enzyme catalysis events, 12 translocations, 83 activation/inhibition reactions, 45 protein expressions and 57 gene regulation events (Supplementary Data S1). These events were further incorporated into the corresponding signaling pathway map (Fig. 1). Information regarding bradykinin signaling events can be obtained from the WikiPathways database (https://www.wikipathwa ys.org/index.php/Pathway:WP5132). The signaling pathway map can be freely downloaded in png, pdf and gpml formats from this database.

\section{Description of the bradykinin signaling pathway}

Bradykinin, a pro-inflammatory nonapeptide, is released by the action of plasma or tissue kallikreins on kininogens (Drouin et al. 1979; Kakoki and Smithies 2009). Signaling by bradykinin is mainly mediated through $\mathrm{B} 2 \mathrm{R}$, a receptor of the seven-transmembrane GPCR family, which are capable of generating a broad spectrum of physiological responses such as vasodilation, fluid balance and retention, smooth muscle contraction, and algesia on target cells (Khasar et al. 1995; Virych et al. 2017). Bradykinin/B2R induces the activation of MAPK1/3 via PKC and $\mathrm{c}-\mathrm{Src}$ pathways, which up-regulates matrix metalloproteinase (MMP)-9 and increases the conventional outflow facility in human trabecular meshwork cells (Webb et al. 2011). Furthermore, bradykinin enhance cell proliferation by the activation of cytosolic calcium, PKC-alpha $(\alpha)$, -beta $(\beta)$, -delta $(\delta)$, -epsilon $(\varepsilon)$ and -eta $(\eta)$ and MAPK1/3 mediated signaling in primary culture of breast cancer cells, pheochromocytoma PC12 cells and ventricular myocytes (Clerk et al. 1996; Graness et al. 1997; Greco et al. 2005). In addition, c-Src phosphorylates FRS2 at Tyr196, leading to the activation of MAPK1/3 and nuclear translocation of STAT3, which ultimately results in the release of FGF-2 protein. The release of FGF-2 mediates various biological effects, including permeability, migration and inflammation in human HREC and HUVEC cell lines (Terzuoli et al. 2018).

Bradykinin mediates signaling modules in various cells such as cardiomyocytes, epithelial cells, fibroblasts and 


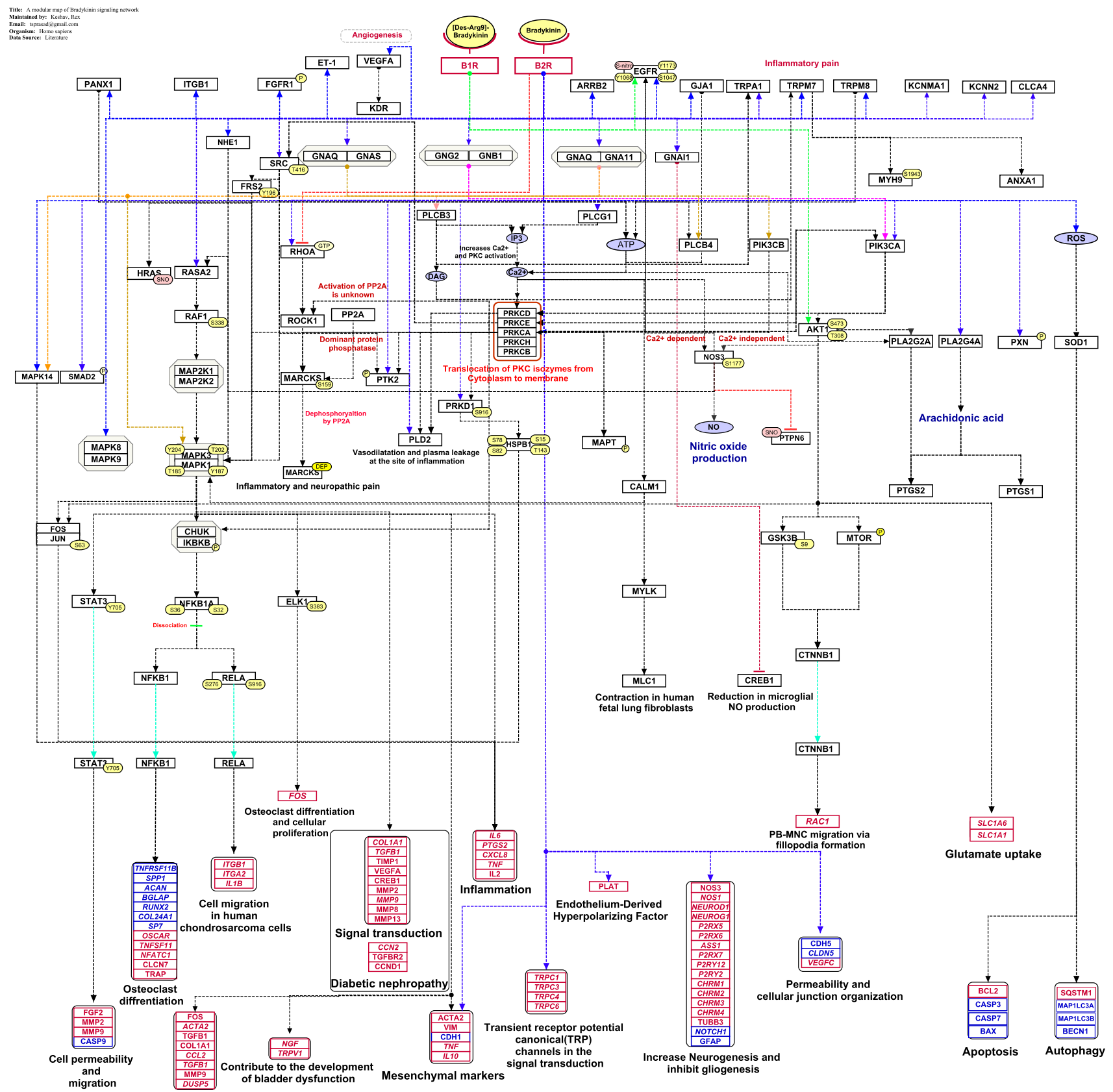

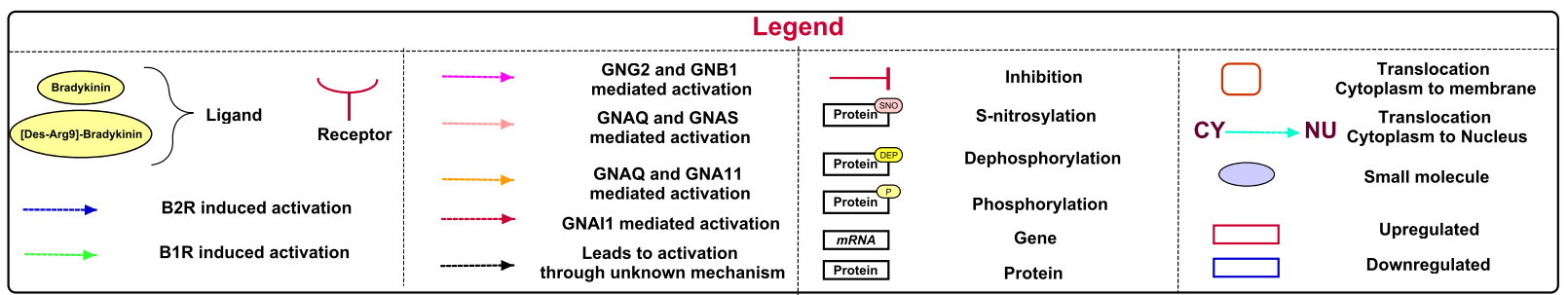

Fig. 1 Schematic representation of bradykinin mediated signaling pathway. The signaling pathway map represents molecules involved in ligand-receptor interactions and bradykinin-activated downstream molecular events including molecular association, catalysis, translo- cation, and gene regulation events. Information regarding the posttranslational modification site and the residue is also shown in the pathway. 
neuroblastoma cells. In synovial fibroblasts, bradykinin stimulates B2R and activates IKK $\alpha / \beta$ (IKK alpha/beta) via the activation of PLC, PKC- $\delta$ (PRKCD) and increases the binding of RELA and NFKB1 to the NF- $\mathrm{KB}$ element, which leads to the increased production of $I L-6$ in rheumatoid arthritis (Lee et al. 2008). In addition, B2R stimulation by bradykinin activates EGFR mediated PI3K activation and translocation of PRKCD from the cytoplasm to the plasma membrane to induce MAPK $1 / 3$ activation and FOS protein expression, which lead to cell proliferation in human breast epithelial cells (Greco et al. 2004). In human cardiac c-kit+ progenitor cells, B2R activation by bradykinin releases $\mathrm{Ca}^{2+}$ from the endoplasmic reticulum and influx through store-operated Ca2+entry (SOCE) complex activates AKT, MAPK1/3 phosphorylation and cyclin D1 protein expression leads to cell proliferation and migration to promote myocardial repair ( $\mathrm{Li}$ et al. 2017). In human neuroblastoma SH-SY5Y cells, bradykinin promotes neurite outgrowth through rapid transient MARCKS phosphorylation through PKC dependent RhoA/ROCK pathway followed by dephosphorylation with the help of protein phosphatase 2A (PP2A) (Tanabe et al. 2012). Bradykinin stimulates myofibroblast migration through Hsp27 phosphorylation and cyclooxygenase 2 (COX2) expression via PKD in the CCD-18Co cell line (Chu et al. 2017). In human ciliary muscle $(\mathrm{CM})$ cells, bradykinin/B2R leads to expression of COX1, and COX2 via MAPK signaling pathway. Subsequent release of PGE2 and PGF2 $\alpha$ to the extracellular space is involved in the modulation of intraocular pressure (IOP) (Sharif et al. 2013).

In addition to MAPK activation, PI3K/AKT/mTOR/ GSK3 $\beta$ is another major signal transducer involved in bradykinin mediated signaling. In human cardiac c-Kit + progenitor cells, PLC-mediated $\mathrm{Ca}^{2+}$ influx through the SOCE channel initiates AKT phosphorylation and CCND1 expression, leading to cell cycle progression and migration ( $\mathrm{Li}$ et al. 2018). In human retinal pigment epithelial (ARPE) cells, bradykinin stimulates PI3K/AKT pathway via B1R and B2R to activate PLA2/COX2-mediated up-regulation of SLC1A6 and SLC1A1, which triggers glutamate uptake (Lim et al. 2008). Bradykinin/B2R/PI3K/eNOS signaling exerts a potent chemoattractant activity on $\mathrm{CD} 133(+)$ and $\mathrm{CD} 34(+)$ circulating angiogenic progenitor cells (CPCs) associated with neovascularization potential (Krankel et al. 2008).

\section{Bradykinin signaling pathway in diseases}

Bradykinin is a potent pro-inflammatory mediator, neutrophil chemoattractant and angiogenic factor, which acts through B1R and B2R in many inflammatory diseases such as chronic pain, vasculopathy, asthma, allergic rhinitis, neuropathy, obesity, rheumatoid arthritis, diabetes, cancer and infectious disease (Barnes 1992; Couture et al. 2001; Wang et al. 2008; Dagnino et al. 2020; Lau et al. 2020). Lysdes[Arg9]-bradykinin/B1R induces the epidermal growth factor receptor (EGFR) and downstream signaling via the MAPK1/3 activation mechanism modulate neutrophils migration by upregulating MMP-2 and MMP-9 in estrogensensitive and -insensitive breast cancer cells (Ehrenfeld et al. 2011). B1R activation upregulates chemokine CXCL5A expression involved in neutrophil recruitment at sites of inflammation (Duchene et al. 2007).

\section{Inflammation}

Bradykinin induced pro-survival and proliferative intracellular signaling in human hepatic stellate cells and rat hepatocytes through AKT mediated NF- $\mathrm{KB}$ translocation and downregulation of TGFBI and COLIAl expression attenuate liver damage and fibrosis (Sancho-Bru et al. 2007). Further, in human airway epithelial cells, bradykinin activates the Ras/Raf-1/MAPK pathway, which in turn leads to the activation of IKK $\alpha / \beta$ and NF-KB and up-regulation of COX2, which is involved in the transition of acute allergic reactions to chronic airway inflammatory diseases, such as asthma (Chen et al. 2004).

Bradykinin triggers the activation of TRPA1 via the PLC and PKA pathways in response to tissue inflammation, which might trigger the sensation of pain in rat DRG neurons (Wang et al. 2008). Bradykinin receptors induce the overexpression of inflammatory cytokines, including $T N F-\alpha$ and $I L-10$, which are involved in inflammation in the human salivary gland cells (Lee et al. 2017). Bradykinin induces the expression of $I L-8$ via the binding of transcription factors AP-1, nuclear factor (NF)-IL-6 and NF- $\mathrm{KB}$ to the $I L-8$ promoter via prostaglandin $\mathrm{E} 2$ dependent and independent activation in human airway smooth muscle cells (Zhu et al. 2003). Recent studies have reported that bradykinin-induced COX-2 expression and PGE2 release via PKC- $\delta$-dependent activation of MAPK1/3 and NF- $\kappa B$ pathways may lead to brain injury and inflammatory diseases in human CM cells, podocytes, rat astrocytes and A549 cells (Chen et al. 2004; Hsieh et al. 2007; Sharif et al. 2013; Saoud et al. 2020). In vulvar vestibule fibroblasts, bradykinin/B2R induces NF-kB activation, which increases the $I L-6$ release and causes pain (Falsetta et al. 2016). In human articular chondrocytes and renal epithelial cells, bradykinin induces the release of inflammatory cytokines such as $I L-6$ and $I L-8$ via NF- $\mathrm{KB}$ signaling mechanism (Meini et al. 2011; Yang et al. 2018).

\section{Cancer}

The bradykinin-mediated B2R triggers NF- $\mathrm{\kappa B}$ activation via $\mathrm{G} \alpha_{\mathrm{qs}}, \mathrm{G} \beta_{1} \gamma_{2}$, PI3K, AKT and IKK2 pathway in HeLa cells (Xie et al. 2000). In A549 lung epithelial cells, bradykinin 
requires $\mathrm{G}_{\mathrm{q} / 11}$ to activate MAPK1/3 and MAPK14, which induces the phosphorylation of EGFR at Ser 1047 and upregulates the transcription of dual-specificity MAPK phosphatase 5 (DUSP5) (Izumi et al. 2018). Bradykinin mediated $\mathrm{B} 2 \mathrm{R}$ activation leads to cell proliferation in human renal carcinoma A498 cells through MAPK1/3 and NHE1 pathways (Kramarenko et al. 2012). Also, bradykinin/B2R promoted the proliferation, migration, and invasion of cervical cancer cells via the STAT3 signaling pathway by upregulating the expression of MMP-2, MMP-9 and downregulating the expression pro-apoptotic protein cleaved caspase-9 (Yang et al. 2009; Wang et al. 2019). Bradykinin enhances cell migration in human prostate cancer cells through B2R/ $\mathrm{PKC} / \mathrm{c}-$ Src-dependent signaling by regulating the expression of MMP-9 via the NF- $\kappa$ B pathway (Yu et al. 2013). In head and neck squamous cell carcinomas, the bradykinin/ B2R activation upregulates COX-2 through the MAPKs pathway in tumorigenesis (Zhang et al. 2008). Bradykinin promotes cell proliferation, migration, invasion, and tumor growth of gastric cancer by upregulation of MMP-2, MMP9, COX-2 and downregulation of E-cadherin via MAPK pathway (Wang et al. 2017).

In various breast cancer cells, bradykinin-induced proliferation through PKC mediated MAPK, PI3K and AKT pathways (Greco et al. 2004, 2005, 2006). Bradykinin/ B2R induced PI3K activation mediates the translocation of PRKCE from the cytosol to plasma membrane in the human colon carcinoma cell line SW-480 (Graness et al. 1998). In human prostate cancer cells, bradykinin/B2R signaling induces VEGF expression leads to angiogenesis through AKT/mTOR/NF-kB/AP-1 pathway (Yu et al. 2014). In the human colorectal cancer cell line SW480, bradykinin increases $I L-6$ production via B2R and the MAPK pathway, contributing to invasion and migration (Wang et al. 2014).

\section{Other diseases}

In mesangial cells, c-Src/MAPK activation by bradykinin induces CTGF, TGF-beta RII, and collagen I expression, which contributes to the development of diabetic nephropathy (Tan et al. 2005). SARS-CoV-2 infection activates inflammatory cytokine storm, which leads to multi-organ injury in the host (Rex et al. 2021). Recent studies reported that dysregulated bradykinin signaling is at the core of most of the symptoms of the SARS-CoV-2 infection. A vicious positive bradykinin feedback loop has been suspected in the progression of the cytokine storm mediated by $I L-6$ and $I L-8$ (Garvin et al. 2020; Roche and Roche 2020). The bradykinin/B2R mediated signaling induces NO production and S-nitrosylation of RAS and EGFR, which activates MAPK1/3 and up-regulates VEGF protein expression leading to angiogenesis in HUVEC cells (Moraes et al. 2014). Several studies reported that bradykinin has an important role in a broad range of human diseases. Therefore, an organized integrative pathway map of bradykinin will provide a platform for accelerating scientific investigation on the role of bradykinin in various diseases.

\section{Drugs that target Bradykinin signaling}

Bradykinin is known to play a role in certain cardiovascular conditions (Blaes and Girolami 2013). In such a state, B2R agonists or ACE inhibitors are employed to enhance bradykinin lifetime and its downstream effects (Jalowy et al. 1998; Campbell et al. 2004). However, the pathological state of chronic inflammation witnessed in Alzheimer's disease due to the elevated levels of bradykinin (Singh et al. 2020a, 2020b). Similarly, overexpression of bradykinin was observed in hereditary angioedema, asthma and COVID19 patients (Hofman et al.2016a, 2016b; Ricciardolo et al. 2018; Garvin et al. 2020). In such conditions, bradykinin effects countered using antagonists like Hoe140, which competitively antagonizes B2R (Wirth et al. 1991). Alternatively, kallikrein inhibitors such as Lanadelumab, Garadacimab, Ecallantide (DX-88), and Berotralstat were used to interfere with PK activity, which hinder HMWK cleavage (Farkas and Varga 2011; Davoine et al. 2020; Manning and Kashkin 2021; Wedner et al. 2021; Zuraw et al. 2021). A recent study reported that a new chemical, compound 3, can antagonize B2R even at a picomolar concentration (Lesage et al. 2020).

\section{Conclusions}

Bradykinin-mediated signaling implicated in inflammation, chronic pain, vasculopathy, neuropathy, obesity, diabetes, and cancer. However, the role of the bradykinin-mediated signaling pathway in inflammatory diseases is still unclear. In-depth data mining and depiction of molecular reactions induced by bradykinin into a spatiotemporally organized signaling network will help the future biomedical investigation in bradykinin signaling. The comprehensive network map of bradykinin signaling will provide several peripheral novel proteins with undefined functionality in the signaling pathway, providing new hypotheses for future research. In addition, an increase in the number of proteins in the bradykinin signaling network will make this pathway linked to various new physiological events when future datasets subjected to gene set enrichment analyses.

Supplementary Information The online version contains supplementary material available at https://doi.org/10.1007/s12079-021-00652-0.

Acknowledgements We acknowledge a research grant from Olav Thon Foundation entitled "Discovering new therapeutic targets and drugs to combat AMR tuberculosis: proteomics characterization and drug 
screening of mycobacterium-infected macrophages." We also thank Karnataka Biotechnology and Information Technology Services (KBITS), Government of Karnataka, for the support to the Center for Systems Biology and Molecular Medicine at Yenepoya (Deemed to be University) under the Biotechnology Skill Enhancement Programme in Multi-Omics Technology (BiSEP GO ITD 02 MDA 2017). RDAB is a recipient of a Senior Research Fellowship from the Indian Council of Medical Research (ICMR), Government of India.

\section{Declarations}

Conflict of interest The authors report no conflicts of interest.

\section{References}

Astuti I and Ysrafil (2020) Severe acute respiratory syndrome coronavirus 2 (SARS-CoV-2): an overview of viral structure and host response. Diabetes Metab Syndr 14(4):407-412

Barnes PJ (1992) Bradykinin and asthma. Thorax 47(11):979-983

Bas M, Adams V, Suvorava T, Niehues T, Hoffmann TK, Kojda G (2007) Nonallergic angioedema: role of bradykinin. Allergy 62(8):842-856

Blaes N, Girolami JP (2013) Targeting the "Janus face" of the B2-bradykinin receptor. Expert Opin Ther Targets 17(10):1145-1166

Bossi F, Fischetti F, Regoli D, Durigutto P, Frossi B, Gobeil F Jr, Ghebrehiwet B, Peerschke EI, Cicardi M, Tedesco F (2009) Novel pathogenic mechanism and therapeutic approaches to angioedema associated with $\mathrm{C} 1$ inhibitor deficiency. J Allergy Clin Immunol 124(6):1303-1310

Campbell DJ, Alexiou T, Xiao HD, Fuchs S, McKinley MJ, Corvol P, Bernstein KE (2004) Effect of reduced angiotensin-converting enzyme gene expression and angiotensin-converting enzyme inhibition on angiotensin and bradykinin peptide levels in mice. Hypertension 43(4):854-859

Chen BC, Yu CC, Lei HC, Chang MS, Hsu MJ, Huang CL, Chen MC, Sheu JR, Chen TF, Chen TL, Inoue H, Lin CH (2004) Bradykinin $\mathrm{B} 2$ receptor mediates NF-kappaB activation and cyclooxygenase-2 expression via the Ras/Raf-1/ERK pathway in human airway epithelial cells. J Immunol 173(8):5219-5228

Chu E, Saini S, Liu T, Yoo J (2017) Bradykinin stimulates protein kinase D-mediated colonic myofibroblast migration via cyclooxygenase-2 and heat shock protein 27. J Surg Res 209:191-198

Clerk A, Gillespie-Brown J, Fuller SJ, Sugden PH (1996) Stimulation of phosphatidylinositol hydrolysis, protein kinase $\mathrm{C}$ translocation, and mitogen-activated protein kinase activity by bradykinin in rat ventricular myocytes: dissociation from the hypertrophic response. Biochem J 317(Pt 1):109-118

Couture R, Harrisson M, Vianna RM, Cloutier F (2001) Kinin receptors in pain and inflammation. Eur J Pharmacol 429(1-3):161-176

da Costa PL, Sirois P, Tannock IF, Chammas R (2014) The role of kinin receptors in cancer and therapeutic opportunities. Cancer Lett 345(1):27-38

Dagamajalu S, Rex DAB, Gopalakrishnan L, Karthikkeyan G, Gurtoo S, Modi PK, Mohanty V, Mujeeburahiman M, Soman S, Raju R, Tiwari V, Prasad TSK (2021a) A network map of endothelin mediated signaling pathway. J Cell Commun Signal 15(2):277-282

Dagamajalu S, Rex DAB, Palollathil A, Shetty R, Bhat G, Cheung LWT, Prasad TSK (2021b) A pathway map of AXL receptor-mediated signaling network. J Cell Commun Signal 15(1):143-148

Dagnino APA, Campos MM, Silva RBM (2020) Kinins and their receptors in infectious diseases. Pharmaceuticals (basel) 13(9):215
Davoine C, Bouckaert C, Fillet M, Pochet L (2020) Factor XII/XIIa inhibitors: their discovery, development, and potential indications. Eur J Med Chem 208:112753

Dey G, Radhakrishnan A, Syed N, Thomas JK, Nadig A, Srikumar K, Mathur PP, Pandey A, Lin SK, Raju R, Prasad TS (2013) Signaling network of oncostatin M pathway. J Cell Commun Signal 7(2):103-108

Dong R, Chen W, Feng W, Xia C, Hu D, Zhang Y, Yang Y, Wang DW, Xu X, Tu L (2015) Exogenous bradykinin inhibits tissue factor induction and deep vein thrombosis via activating the eNOS/Phosphoinositide 3-Kinase/Akt signaling pathway. Cell Physiol Biochem 37(4):1592-1606

Drouin JN, St-Pierre SA, Regoli D (1979) Receptors for bradykinin and kallidin. Can J Physiol Pharmacol 57(4):375-379

Duchene J, Lecomte F, Ahmed S, Cayla C, Pesquero J, Bader M, Perretti M, Ahluwalia A (2007) A novel inflammatory pathway involved in leukocyte recruitment: role for the kinin B1 receptor and the chemokine CXCL5. J Immunol 179(7):4849-4856

Ehrenfeld P, Conejeros I, Pavicic MF, Matus CE, Gonzalez CB, Quest AF, Bhoola KD, Poblete MT, Burgos RA, Figueroa CD (2011) Activation of kinin B1 receptor increases the release of metalloproteases-2 and -9 from both estrogen-sensitive and -insensitive breast cancer cells. Cancer Lett 301(1):106-118

Falsetta ML, Foster DC, Woeller CF, Pollock SJ, Bonham AD, Haidaris CG, Phipps RP (2016) A role for bradykinin signaling in chronic vulvar pain. J Pain 17(11):1183-1197

Farkas H, Varga L (2011) Ecallantide is a novel treatment for attacks of hereditary angioedema due to $\mathrm{C} 1$ inhibitor deficiency. Clin Cosmet Investig Dermatol 4:61-68

Fong D, Smith DI, Hsieh WT (1991) The human kininogen gene (KNG) mapped to chromosome 3q26-qter by analysis of somatic cell hybrids using the polymerase chain reaction. Hum Genet 87(2):189-192

Garvin MR, Alvarez C, Miller JI, Prates ET, Walker AM, Amos BK, Mast AE, Justice A, Aronow B, Jacobson D (2020) A mechanistic model and therapeutic interventions for COVID-19 involving a RAS-mediated bradykinin storm. Elife 9:e59177. https://doi.org/10.7554/eLife.59177

Graness A, Adomeit A, Ludwig B, Muller WD, Kaufmann R, Liebmann C (1997) Novel bradykinin signalling events in PC-12 cells: stimulation of the cAMP pathway leads to cAMPmediated translocation of protein kinase Cepsilon. Biochem J 327(Pt 1):147-154

Graness A, Adomeit A, Heinze R, Wetzker R, Liebmann C (1998) A novel mitogenic signaling pathway of bradykinin in the human colon carcinoma cell line SW-480 involves sequential activation of a Gq/11 protein phosphatidylinositol 3-kinase $\beta$ and protein kinase Ce. J Biol Chem 273(48):32016-32022. https:// doi.org/10.1074/jbc.273.48.32016

Greco S, Muscella A, Elia MG, Romano S, Storelli C, Marsigliante S (2004) Mitogenic signalling by B2 bradykinin receptor in epithelial breast cells. J Cell Physiol 201(1):84-96

Greco S, Elia MG, Muscella A, Romano S, Storelli C, Marsigliante $S$ (2005) Bradykinin stimulates cell proliferation through an extracellular-regulated kinase 1 and 2-dependent mechanism in breast cancer cells in primary culture. J Endocrinol 186(2):291-301

Greco S, Storelli C, Marsigliante S (2006) Protein kinase C (PKC)delta/-epsilon mediate the PKC/Akt-dependent phosphorylation of extracellular signal-regulated kinases 1 and 2 in MCF-7 cells stimulated by bradykinin. J Endocrinol 188(1):79-89

Hofman Z, de Maat S, Hack CE, Maas C (2016a) Bradykinin: inflammatory product of the coagulation system. Clin Rev Allergy Immunol 51(2):152-161

Hofman ZL, Relan A, Zeerleder S, Drouet C, Zuraw B, Hack CE (2016b) Angioedema attacks in patients with hereditary 
angioedema: local manifestations of a systemic activation process. J Allergy Clin Immunol 138(2):359-366

Hsieh HL, Wang HH, Wu CY, Jou MJ, Yen MH, Parker P, Yang CM (2007) BK-induced COX-2 expression via PKC-delta-dependent activation of $\mathrm{p} 42 / \mathrm{p} 44$ MAPK and NF-kappaB in astrocytes. Cell Signal 19(2):330-340

Huang CD, Tliba O, Panettieri RA Jr, Amrani Y (2003) Bradykinin induces interleukin- 6 production in human airway smooth muscle cells: modulation by Th2 cytokines and dexamethasone. Am J Respir Cell Mol Biol 28(3):330-338

Izumi S, Higa-Nakamine $\mathrm{S}$, Nishi $\mathrm{H}$, Torihara $\mathrm{H}$, Uehara A, Sugahara K, Kakinohana M, Yamamoto H (2018) Phosphorylation of epidermal growth factor receptor at serine 1047 in cultured lung alveolar epithelial cells by bradykinin B2 receptor stimulation. Pulm Pharmacol Ther 48:53-61

Jaffa MA, Kobeissy F, Al Hariri M, Chalhoub H, Eid A, Ziyadeh FN, Jaffa AA (2012) Global renal gene expression profiling analysis in B2-kinin receptor null mice: impact of diabetes. PLoS ONE 7(9):e44714

Jalowy A, Schulz R, Dorge H, Behrends M, Heusch G (1998) Infarct size reduction by AT1-receptor blockade through a signal cascade of AT2-receptor activation, bradykinin and prostaglandins in pigs. J Am Coll Cardiol 32(6):1787-1796

Kakoki M, Smithies O (2009) The kallikrein-kinin system in health and in diseases of the kidney. Kidney Int 75(10):1019-1030

Kandasamy K, Keerthikumar S, Raju R, Keshava Prasad TS, Ramachandra YL, Mohan S, Pandey A (2009) PathBuilderopen source software for annotating and developing pathway resources. Bioinformatics 25(21):2860-2862

Kandasamy K, Mohan SS, Raju R, Keerthikumar S, Kumar GS, Venugopal AK, Telikicherla D, Navarro JD, Mathivanan S, Pecquet C, Gollapudi SK, Tattikota SG, Mohan S, Padhukasahasram H, Subbannayya Y, Goel R, Jacob HK, Zhong J, Sekhar R, Nanjappa V, Balakrishnan L, Subbaiah R, Ramachandra YL, Rahiman BA, Prasad TS, Lin JX, Houtman JC, Desiderio S, Renauld JC, Constantinescu SN, Ohara O, Hirano T, Kubo M, Singh S, Khatri P, Draghici S, Bader GD, Sander C, Leonard WJ, Pandey A (2010) NetPath: a public resource of curated signal transduction pathways. Genome Biol 11(1):R3

Kaplan AP, Joseph K, Silverberg M (2002) Pathways for bradykinin formation and inflammatory disease. J Allergy Clin Immunol 109(2):195-209

Kenniston JA, Faucette RR, Martik D, Comeau SR, Lindberg AP, Kopacz KJ, Conley GP, Chen J, Viswanathan M, Kastrapeli N, Cosic J, Mason S, DiLeo M, Abendroth J, Kuzmic P, Ladner RC, Edwards TE, TenHoor C, Adelman BA, Nixon AE, Sexton DJ (2014) Inhibition of plasma kallikrein by a highly specific active site blocking antibody. J Biol Chem 289(34):23596-23608

Khasar SG, Miao FJ, Levine JD (1995) Inflammation modulates the contribution of receptor-subtypes to bradykinin-induced hyperalgesia in the rat. Neuroscience 69(2):685-690

Kmietowicz Z (2018) ACE inhibitors are linked to increased lung cancer risk, study finds. BMJ 363:k4471

Kramarenko II, Morinelli TA, Bunni MA, Raymond JR Sr, Garnovskaya MN (2012) The bradykinin B(2) receptor induces multiple cellular responses leading to the proliferation of human renal carcinoma cell lines. Cancer Manag Res 4:195-205

Krankel N, Katare RG, Siragusa M, Barcelos LS, Campagnolo P, Mangialardi G, Fortunato O, Spinetti G, Tran N, Zacharowski K, Wojakowski W, Mroz I, Herman A, Manning Fox JE, MacDonald PE, Schanstra JP, Bascands JL, Ascione R, Angelini G, Emanueli C, Madeddu P (2008) Role of kinin B2 receptor signaling in the recruitment of circulating progenitor cells with neovascularization potential. Circ Res 103(11):1335-1343
Kutmon M, van Iersel MP, Bohler A, Kelder T, Nunes N, Pico AR, Evelo CT (2015) PathVisio 3: an extendable pathway analysis toolbox. PLoS Comput Biol 11(2):e1004085

Lau J, Rousseau J, Kwon D, Benard F, Lin KS (2020) A systematic review of molecular imaging agents targeting bradykinin $\mathrm{B} 1$ and B2 receptors. Pharmaceuticals (basel) 13(8):199

Lee $\mathrm{CH}$, Shieh DC, Tzeng CY, Chen CP, Wang SP, Chiu YC, Huang CY, Hsu CJ, Fong YC, Tang CH (2008) Bradykinin-induced IL-6 expression through bradykinin $\mathrm{B} 2$ receptor, phospholipase $\mathrm{C}$, protein kinase Cdelta and NF-kappaB pathway in human synovial fibroblasts. Mol Immunol 45(14):3693-3702

Lee K, Kim YJ, Choi LM, Choi S, Nam H, Ko HY, Chung G, Lee JH, Jo SH, Lee G, Choi SY, Park K (2017) Human salivary gland cells express bradykinin receptors that modulate the expression of proinflammatory cytokines. Eur J Oral Sci 125(1):18-27

Leeb-Lundberg LM, Marceau F, Muller-Esterl W, Pettibone DJ, Zuraw BL (2005) International union of pharmacology. XLV. Classification of the kinin receptor family: from molecular mechanisms to pathophysiological consequences. Pharmacol Rev 57(1):27-77

Lesage A, Gibson C, Marceau F, Ambrosi HD, Saupe J, Katzer W, Loenders B, Charest-Morin X, Knolle J (2020) In vitro pharmacological profile of a new small molecule bradykinin B2 receptor antagonist. Front Pharmacol 11:916

Li G, Wang Y, Li GR (2017) Bradykinin regulates cell growth and migration in cultured human cardiac c-Kit+ progenitor cells. Oncotarget 8(7):10822-10835

Li G, Che H, Wu WY, Jie LJ, Xiao GS, Wang Y, Li GR (2018) Bradykinin-mediated $\mathrm{Ca}(2+)$ signalling regulates cell growth and mobility in human cardiac c-Kit(+) progenitor cells. J Cell Mol Med 22(10):4688-4699

Lim SK, Park MJ, Jung HK, Park AY, Kim DI, Kim JC, Bae CS, Kim KY, Yoon KC, Han HJ, Park SH (2008) Bradykinin stimulates glutamate uptake via both B1R and B2R activation in a human retinal pigment epithelial cells. Life Sci 83(23-24):761-770

Manning ME, Kashkin JM (2021) Berotralstat (BCX7353) is a novel oral prophylactic treatment for hereditary angioedema: Review of phase II and III studies. Allergy Asthma Proc 42(4):274-282

Marceau F, Sabourin T, Houle S, Fortin JP, Petitclerc E, Molinaro G, Adam A (2002) Kinin receptors: functional aspects. Int Immunopharmacol 2(13-14):1729-1739

Marceau F, Bachelard H, Bouthillier J, Fortin JP, Morissette G, Bawolak MT, Charest-Morin X, Gera L (2020) Bradykinin receptors: agonists, antagonists, expression, signaling, and adaptation to sustained stimulation. Int Immunopharmacol 82:106305

Meini S, Cucchi P, Catalani C, Bellucci F, Giuliani S, Maggi CA (2011) Bradykinin and $\mathrm{B}(2)$ receptor antagonism in rat and human articular chondrocytes. Br J Pharmacol 162(3):611-622

Moraes MS, Costa PE, Batista WL, Paschoalin T, Curcio MF, Borges RE, Taha MO, Fonseca FV, Stern A, Monteiro HP (2014) Endothelium-derived nitric oxide (NO) activates the NO-epidermal growth factor receptor-mediated signaling pathway in bradykinin-stimulated angiogenesis. Arch Biochem Biophys 558:14-27. https://doi.org/10.1016/j.abb.2014.06.011

Motta Junior JDS, Miggiolaro A, Nagashima S, de Paula CBV, Baena CP, Scharfstein J, de Noronha L (2020) Mast cells in alveolar septa of COVID-19 patients: a pathogenic pathway that may link interstitial edema to immunothrombosis. Front Immunol 11:574862

Naffah-Mazzacoratti Mda G, Gouveia TL, Simoes PS, Perosa SR (2014) What have we learned about the kallikrein-kinin and renin-angiotensin systems in neurological disorders? World J Biol Chem 5(2):130-140

Nokkari A, Abou-El-Hassan H, Mechref Y, Mondello S, Kindy MS, Jaffa AA, Kobeissy F (2018) Implication of the Kallikrein-Kinin system in neurological disorders: quest for potential biomarkers and mechanisms. Prog Neurobiol 165-167:26-50 
Paegelow I, Werner H, Vietinghoff G, Wartner U (1995) Release of cytokines from isolated lung strips by bradykinin. Inflamm Res 44(7):306-311

Pan ZK, Zuraw BL, Lung CC, Prossnitz ER, Browning DD, Ye RD (1996) Bradykinin stimulates NF-kappaB activation and interleukin 1 beta gene expression in cultured human fibroblasts. J Clin Invest 98(9):2042-2049

Pinto SM, Subbannayya Y, Rex DAB, Raju R, Chatterjee O, Advani J, Radhakrishnan A, Keshava Prasad TS, Wani MR, Pandey A (2018) A network map of IL-33 signaling pathway. J Cell Commun Signal 12(3):615-624

Qadri F, Bader M (2018) Kinin B1 receptors as a therapeutic target for inflammation. Expert Opin Ther Targets 22(1):31-44

Raju R, Nanjappa V, Balakrishnan L, Radhakrishnan A, Thomas JK, Sharma J, Tian M, Palapetta SM, Subbannayya T, Sekhar NR, Muthusamy B, Goel R, Subbannayya Y, Telikicherla D, Bhattacharjee M, Pinto SM, Syed N, Srikanth MS, Sathe GJ, Ahmad S, Chavan SN, Kumar GS, Marimuthu A, Prasad TS, Harsha HC, Rahiman BA, Ohara O, Bader GD, Sujatha Mohan S, Schiemann WP, Pandey A (2011) NetSlim: high-confidence curated signaling maps. Database (oxford) 2011:bae032

Rex DAB, Agarwal N, Prasad TSK, Kandasamy RK, Subbannayya Y, Pinto SM (2020) A comprehensive pathway map of IL18-mediated signalling. J Cell Commun Signal 14(2):257-266

Rex DAB, Dagamajalu S, Kandasamy RK, Raju R, and Prasad, TSK (2021) SARS-CoV-2 signaling pathway map: A functional landscape of molecular mechanisms in COVID-19. J Cell Commun Signal

Ricciardolo FLM, Folkerts G, Folino A, Mognetti B (2018) Bradykinin in asthma: modulation of airway inflammation and remodelling. Eur J Pharmacol 827:181-188

Roche JA, Roche R (2020) A hypothesized role for dysregulated bradykinin signaling in COVID-19 respiratory complications. FASEB J 34(6):7265-7269

Sancho-Bru P, Bataller R, Fernandez-Varo G, Moreno M, Ramalho LN, Colmenero J, Mari M, Claria J, Jimenez W, Arroyo V, Brenner DA, Gines P (2007) Bradykinin attenuates hepatocellular damage and fibrosis in rats with chronic liver injury. Gastroenterology 133(6):2019-2028

Saoud R, Jaffa MA, Habib A, Zhao J, Al Hariri M, Zhu R, Hasan A, Ziyadeh FN, Kobeissy F, Mechref Y, Jaffa AA (2020) Modulation of proteomic and inflammatory signals by Bradykinin in podocytes. J Adv Res 24:409-422

Sharif NA, Xu S, Li L, Katoli P, Kelly CR, Wang Y, Cao S, Patil R, Husain S, Klekar L, Scott D (2013) Protein expression, biochemical pharmacology of signal transduction, and relation to intraocular pressure modulation by bradykinin $\mathrm{B}(2)$ receptors in ciliary muscle. Mol vis 19:1356-1370

Singh PK, Chen ZL, Ghosh D, Strickland S, Norris EH (2020a) Increased plasma bradykinin level is associated with cognitive impairment in Alzheimer's patients. Neurobiol Dis 139:104833

Singh PK, Chen ZL, Strickland S, Norris EH (2020b) Increased contact system activation in mild cognitive impairment patients with impaired short-term memory. J Alzheimers Dis 77(1):59-65

Soman S, Raju R, Sandhya VK, Advani J, Khan AA, Harsha HC, Prasad TS, Sudhakaran PR, Pandey A, Adishesha PK (2013) A multicellular signal transduction network of AGE/RAGE signaling. J Cell Commun Signal 7(1):19-23

Stewart JM, Gera L, Chan DC, Bunn PA Jr, York EJ, Simkeviciene V, Helfrich B (2002) Bradykinin-related compounds as new drugs for cancer and inflammation. Can J Physiol Pharmacol 80(4):275-280

Tan Y, Wang B, Keum JS, Jaffa AA (2005) Mechanisms through which bradykinin promotes glomerular injury in diabetes. Am J Physiol Renal Physiol 288(3):F483-F492
Tanabe A, Shiraishi M, Negishi M, Saito N, Tanabe M, Sasaki Y (2012) MARCKS dephosphorylation is involved in bradykinininduced neurite outgrowth in neuroblastoma SH-SY5Y cells. J Cell Physiol 227(2):618-629

Terzuoli E, Corti F, Nannelli G, Giachetti A, Donnini S, Ziche M (2018) Bradykinin B2 receptor contributes to inflammatory responses in human endothelial cells by the transactivation of the fibroblast growth factor receptor FGFR-1. Int J Mol Sci 19(9):2638

Tschope C, Schultheiss HP, Walther T (2002) Multiple interactions between the renin-angiotensin and the kallikrein-kinin systems: role of ACE inhibition and AT1 receptor blockade. J Cardiovasc Pharmacol 39(4):478-487

Vandell AG, Larson N, Laxmikanthan G, Panos M, Blaber SI, Blaber M, Scarisbrick IA (2008) Protease-activated receptor dependent and independent signaling by kallikreins 1 and 6 in CNS neuron and astroglial cell lines. J Neurochem 107(3):855-870

Verma R, Balakrishnan L, Sharma K, Khan AA, Advani J, Gowda H, Tripathy SP, Suar M, Pandey A, Gandotra S, Prasad TS, Shankar S (2016) A network map of Interleukin-10 signaling pathway. J Cell Commun Signal 10(1):61-67

Virych PA, Shelyuk OV, Kabanova TA, Khalimova EI, Martynyuk VS, Pavlovsky VI, Andronati SA (2017) Effect of 3-substituted 1,4-benzodiazepin-2-ones on bradykinin-induced smooth muscle contraction. Ukr Biochem J 89(1):31-37

Wang S, Dai Y, Fukuoka T, Yamanaka H, Kobayashi K, Obata K, Cui X, Tominaga M, Noguchi K (2008) Phospholipase C and protein kinase A mediate bradykinin sensitization of TRPA1: a molecular mechanism of inflammatory pain. Brain 131(Pt 5):1241-1251

Wang G, Ye Y, Zhang X, Song J (2014) Bradykinin stimulates IL-6 production and cell invasion in colorectal cancer cells. Oncol Rep 32(4):1709-1714

Wang G, Sun J, Liu G, Fu Y, Zhang X (2017) Bradykinin promotes cell proliferation, migration, invasion, and tumor growth of gastric cancer through ERK signaling pathway. J Cell Biochem 118(12):4444-4453

Wang W, Zhou Y, Wei R, Jiang G, Li F, Chen X, Wang X, Ma D, Xi L (2019) Bradykinin promotes proliferation migration and invasion of cervical cancer cells through STAT3 signaling pathways. Oncol Rep. https://doi.org/10.3892/or.2019.7380

Webb JG, Yang X, Crosson CE (2011) Bradykinin activation of extracellular signal-regulated kinases in human trabecular meshwork cells. Exp Eye Res 92(6):495-501

Wedner HJ, Aygoren-Pursun E, Bernstein J, Craig T, Gower R, Jacobs JS, Johnston DT, Lumry WR, Zuraw BL, Best JM, Iocca HA, Murray SC, Desai B, Nagy E, Sheridan WP, Kiani-Alikhan S (2021) Randomized trial of the efficacy and safety of berotralstat (BCX7353) as an oral prophylactic therapy for hereditary angioedema: results of APeX-2 through 48 weeks (Part 2). J Allergy Clin Immunol Pract 9(6):2305-2314e4

Whalley ET, Figueroa CD, Gera L, Bhoola KD (2012) Discovery and therapeutic potential of kinin receptor antagonists. Expert Opin Drug Discov 7(12):1129-1148

Wilczynski SA, Wenceslau CF, McCarthy CG, Webb RC (2021) A cytokine/bradykinin storm comparison: What is the relationship between hypertension and COVID-19? Am J Hypertens 34(4):304-306

Wirth K, Hock FJ, Albus U, Linz W, Alpermann HG, Anagnostopoulos H, Henk S, Breipohl G, Konig W, Knolle J et al (1991) Hoe 140 a new potent and long acting bradykinin-antagonist: in vivo studies. Br J Pharmacol 102(3):774-777

Xie P, Browning DD, Hay N, Mackman N, Ye RD (2000) Activation of NF- $\kappa B$ by bradykinin through a $G \alpha_{\mathrm{q}}$ - and $\mathrm{G} \beta \gamma$-dependent pathway that involves phosphoinositide 3-kinase and Akt. J Biol Chem 275(32):24907-24914. https://doi.org/10.1074/jbc.M0010 51200 
Yang W-H, Jung-Tzu, Chang Sheng-Feng, Hsu Te-Mao, Li Der-Yang, Cho Chun-Yin, Huang Yi-Chin, Fong Chih-Hsin, Tang (2009) Bradykinin enhances cell migration in human chondrosarcoma cells through BK receptor signaling pathways. J Cell Biochem https://doi.org/10.1002/jcb.22383

Yang L, Zhang J, Li N, Xie H, Chen S, Wang H, Shen T, Zhu QX (2018) Bradykinin receptor in immune-mediated renal tubular injury in trichloroethylene-sensitized mice: impact on NF-kappaB signaling pathway. J Immunotoxicol 15(1):126-136

Yu HS, Lin TH, Tang CH (2013) Bradykinin enhances cell migration in human prostate cancer cells through B2 receptor/PKCdelta/c-Src dependent signaling pathway. Prostate 73(1):89-100

Yu HS, Wang SW, Chang AC, Tai HC, Yeh HI, Lin YM, Tang CH (2014) Bradykinin promotes vascular endothelial growth factor expression and increases angiogenesis in human prostate cancer cells. Biochem Pharmacol 87(2):243-253

Zhang W, Bhola N, Kalyankrishna S, Gooding W, Hunt J, Seethala R, Grandis JR, Siegfried JM (2008) Kinin b2 receptor mediates induction of cyclooxygenase- 2 and is overexpressed in head and neck squamous cell carcinomas. Mol Cancer Res 6(12):1946-1956

Zhang H, Penninger JM, Li Y, Zhong N, Slutsky AS (2020) Angiotensin-converting enzyme 2 (ACE2) as a SARS-CoV-2 receptor: molecular mechanisms and potential therapeutic target. Intensive Care Med 46(4):586-590
Zhu YM, Bradbury DA, Pang L, Knox AJ (2003) Transcriptional regulation of interleukin (IL)-8 by bradykinin in human airway smooth muscle cells involves prostanoid-dependent activation of AP-1 and nuclear factor (NF)-IL-6 and prostanoid-independent activation of NF-kappaB. J Biol Chem 278(31):29366-29375

Zhu L, Carretero OA, Liao TD, Harding P, Li H, Sumners C, Yang XP (2010) Role of prolylcarboxypeptidase in angiotensin II type 2 receptor-mediated bradykinin release in mouse coronary artery endothelial cells. Hypertension 56(3):384-390

Zuraw B, Lumry WR, Johnston DT, Aygoren-Pursun E, Banerji A, Bernstein JA, Christiansen SC, Jacobs JS, Sitz KV, Gower RG, Gagnon R, Wedner HJ, Kinaciyan T, Hakl R, Hanzlikova J, Anderson JT, McNeil DL, Fritz SB, Yang WH, Tachdjian R, Busse PJ, Craig TJ, Li HH, Farkas H, Best JM, Clemons D, Cornpropst M, Dobo SM, Iocca HA, Kargl D, Nagy E, Murray SC, Collis P, Sheridan WP, Maurer M, Riedl MA (2021) Oral oncedaily berotralstat for the prevention of hereditary angioedema attacks: a randomized, double-blind, placebo-controlled phase 3 trial. J Allergy Clin Immunol 148(1):164-1729

Publisher's Note Springer Nature remains neutral with regard to jurisdictional claims in published maps and institutional affiliations. 